\title{
Effect of Friction Stir Welding Tool Design on Welding Thermal Efficiency
}

Hongjun $\mathrm{Li}^{* a}$, Jian $\mathrm{Gao}^{\mathrm{a}}$, Qinchuan $\mathrm{Li}^{\mathrm{a}}$, Alexander Galloway ${ }^{\mathrm{b}}$, Athanasios

Toumpis ${ }^{b}$

a Faculty of Mechanical Engineering and Automation, Zhejiang Sci-Tech University,

Xiasha Higher Education Zone, Hangzhou 310018, China.

b Department of Mechanical \& Aerospace Engineering, University of Strathclyde,

James Weir Building, 75 Montrose Street, Glasgow G1 1XJ, UK.

*Corresponding author, Tel: +86-18968041257, Fax: +86-571-86843354, E-mail:

lihongjun@zstu.edu.cn. 


\title{
Effect of Friction Stir Welding Tool Design on Welding Thermal Efficiency
}

\begin{abstract}
Enhancing the heat transfer to the material being welded, instead of the tool, will improve the welding thermal efficiency. Friction stir welding of $5 \mathrm{~mm}$ thick 6061-T6 aluminium alloy plates was carried out with the newly produced tools. It was found that the thermal efficiency increased by $4.2 \%$ using a tool with all the new design features (i.e. hollow, fluted and thermally insulated) compared to the conventional tool for aluminium welding. To assess the benefits of the new tool design on steel FSW, a finite element numerical simulation study was undertaken. In this case, the simulation results yielded a welding thermal efficiency increase of $10-15 \%$ using a thermally coated tool, thereby offering potential productivity gains.
\end{abstract}

Keywords: friction stir welding, heat transfer, FE model, heat insulation, FSW tool, welding thermal efficiency

\section{Introduction}

A steel friction stir welding (FSW) tool is typically used for welding aluminium, magnesium and other low melting point alloys during the FSW process [1]. During welding, the heat generated from the combined effects of friction and plastic deformation is transferred into both the tool and workpiece. The heat transfer ratio between these two components depends on the thermal properties of each material [2]. The beneficial thermal energy is conducted into the workpiece to soften and plasticise the material, but the remaining thermal energy is lost to the tool by either convection to air or conduction to the machine spindle. The welding thermal efficiency $\eta$ is the ratio of the heat flow into the workpiece over the total heat generated [3], assuming that all of the mechanical power is converted into heat and through the weld and tool. Song et al. [4] estimated that the ratio of heat conducted to the tool and workpiece was dependent on the ratio of the tool material conductivity to the workpiece conductivity. When using 
a $\mathrm{WC}$ or pcBN tool to friction stir weld steel (conductivity data given in Table 1 and Table 2), substantially more thermal energy is lost through the tool, resulting in a lower welding thermal efficiency. From this, it is evident that a reduction in the overall thermal energy loss during FSW will improve the process efficiency. This is an important factor as it allows the majority of the generated heat to be transferred directly to the workpiece, thereby enhancing plastic deformation and, potentially, the rate of welding.

Since the invention of FSW, many scientific research articles on the heat transfer of the process have been published [5-9] and have mainly focused on the heat generation mechanism, experimental measurement of temperature, in addition to the analytical and numerical modelling of the heat transfer behaviour. However, a limited body of work has been published on the welding thermal efficiency or on ways of enhancing it. Dickerson et al. [3] carried out the welding of two light alloys with solid steel tools. The heat transfer model for the tool was simulated and validated by the temperature values determined from the tool tempering colours. It was found that the use of grooves in the tool to impede heat flow could be used as a way of increasing welding efficiency. Chao et al. [10] simulated the heat transfer of the FSW process with a steady state boundary value model for the tool and a transient model for the workpiece. The study showed that only about $5 \%$ of the heat generated flows to the tool and the rest goes to the workpiece. Khandkar et al. [11], Simar et al. [12] and Feng et al. [13] built numerical models to study the heat transfer behavor in the process, however, the assumed thermal efficiency values were used rather than calculated by the model. Schmidt et al. [14] developed a thermal model where the total heat generation was not an input parameter, but was actually calculated by comparing the measured temperature profiles and the modelling results. For the welding of Al 7075 T6, the welding thermal 
efficiency was found as $88 \%$. Lienert et al. [15] produced friction stir welds of hotrolled AISI 1018 steel with both molybdenum- and tungsten-based alloys. The heat dissipated in heating the tool was estimated as the product of flux and the crosssectional area of the tool, and the total heat input was calculated by torque and rotation speed. Zhu et al. [16] performed an inverse analysis method based on the experimental data. It was found that only $50 \%$ of the total mechanical energy flowed into the 314 stainless steel workpiece. The thermal efficiency of FSW available in the literature was tabulated in Table 3. It is obvious that the thermal efficiency varies with different workpiece material, tool material and welding parameters.

In all cases, the above discussed literature employed conventional FSW tooling as part of their studies. However, previous works [17-19] indicated that the geometry of tool influenced the weld quality and process response during welding. In a prior published work of this research group [20], 12 FSW tools with different geometric structures were investigated. By comparing the numerically predicted temperature distributions of the tool to the experimental results, it was found that reduction in the heat dissipation from the tool was achieved through the application of thermally insulated tooling. As an extension to the previous research [20], the present study explores the gain in thermal efficiency when a combination of thermal barrier coatings and geometrical changes to the FSW tool design are implemented.

\section{Methodology}

\section{Tool Design}

Based on the FE heat transfer simulations in [20], the following modifications to the conventional FSW tool (Figure 1(a)) were found to be effective in reducing the tool heat loss. The first was the reduction of its main body diameter. Additionally, a hole was drilled along the tool centreline. The purpose of these modifications was the reduction 
of the cross sectional area (Figure 1(b)) and corresponding conducted heat. To further decrease the heat conducted to the tool shank, a series of grooves were introduced (Figure 1(c)). An Y2O3 stabilized $\mathrm{ZrO} 2$ thermal barrier coating was plasma sprayed on the tool shank surface to improve the insulation performance of the tool. Five tools with these thermal insulation features were fabricated as shown in Figure 2.
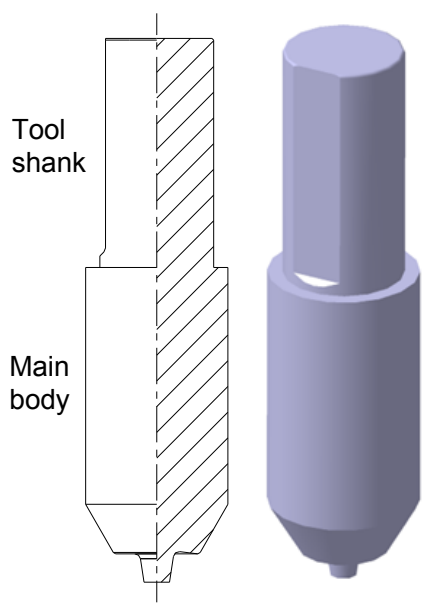

(a) Conventional tool

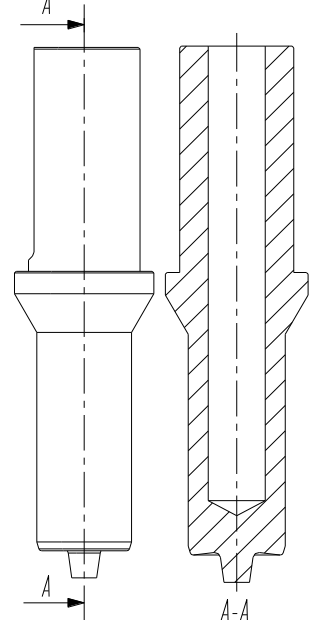

(b) Hollow structure (Tool 1)

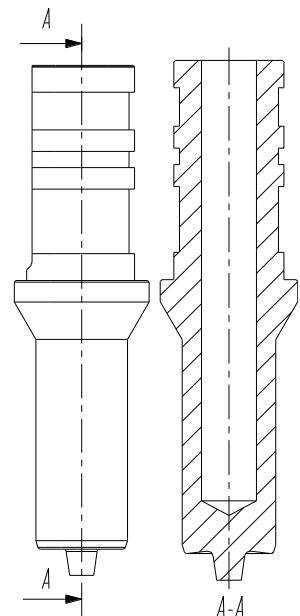

(c)

Shank with flute (Tool 2)

Figure 1. FSW tools with different structures.

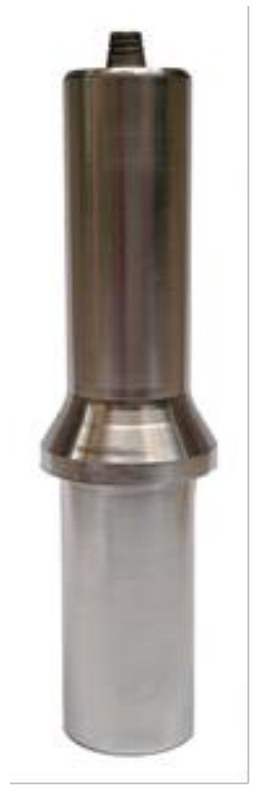

Hollow structure

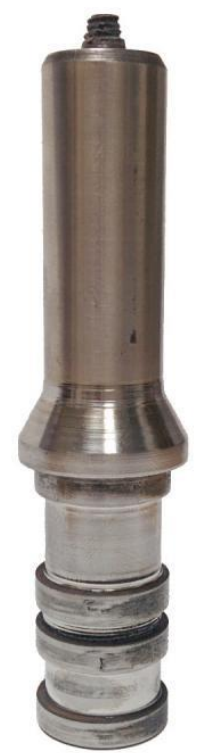

Shank with flute

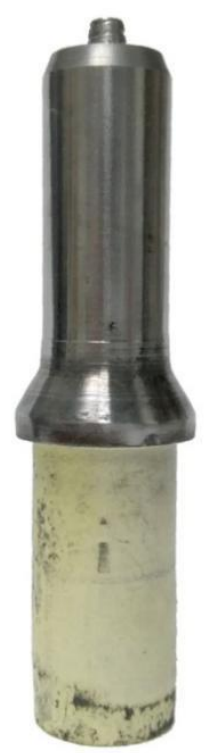

Hollow structure with

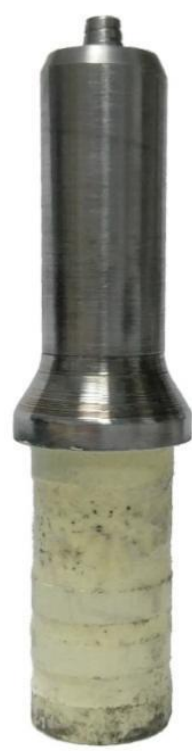

Shank with flute and

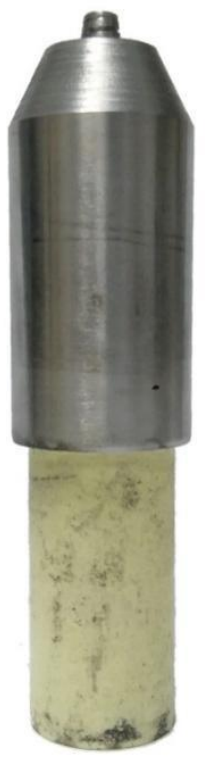

Conventional

$$
\text { coating }
$$

coating tool with coating
(c) Tool 3
(d) Tool 4
(e) Tool 5
(a) Tool 1
(b) Tool 2

SW tools with heat insulation features [20] 


\section{Temperature measurements}

Aluminium alloy $6061-\mathrm{T} 6$ plates of $300 \times 75 \times 5 \mathrm{~mm}$ were used as the workpiece and these were friction stir welded with the parameters: rotational speed, $800 \mathrm{r} / \mathrm{min}$, traverse speed, $30 \mathrm{~mm} / \mathrm{min}$, plunge depth of the shoulder, $0.3 \mathrm{~mm}$. Since it is inconvenient to measure the temperature of the rotating FSW tool with contact type sensors, a FLIR A320 infrared thermal imager was utilised to obtain the temperature field of the tool. The welding plate temperature was measured by inserting K-type armoured thermocouples into the measurement hole drilled on the surface of the plate.

\section{Thermal modelling}

The welding thermal efficiency depends on the heat power into the workpiece and the tool as discussed in the introduction section. These were calculated by independent heat transfer models for the tool and workpiece. The models were created in Abaqus with DC3D20 heat transfer brick element. For the tool thermal model, both the tool and tool holder were included in the analysis as illustrated in Figure 3. The ttemperature dependent thermal properties of the tool materials for welding aluminium was given in Table 1 and constant tool material properties were used for steel welding and shown in Table 2. 


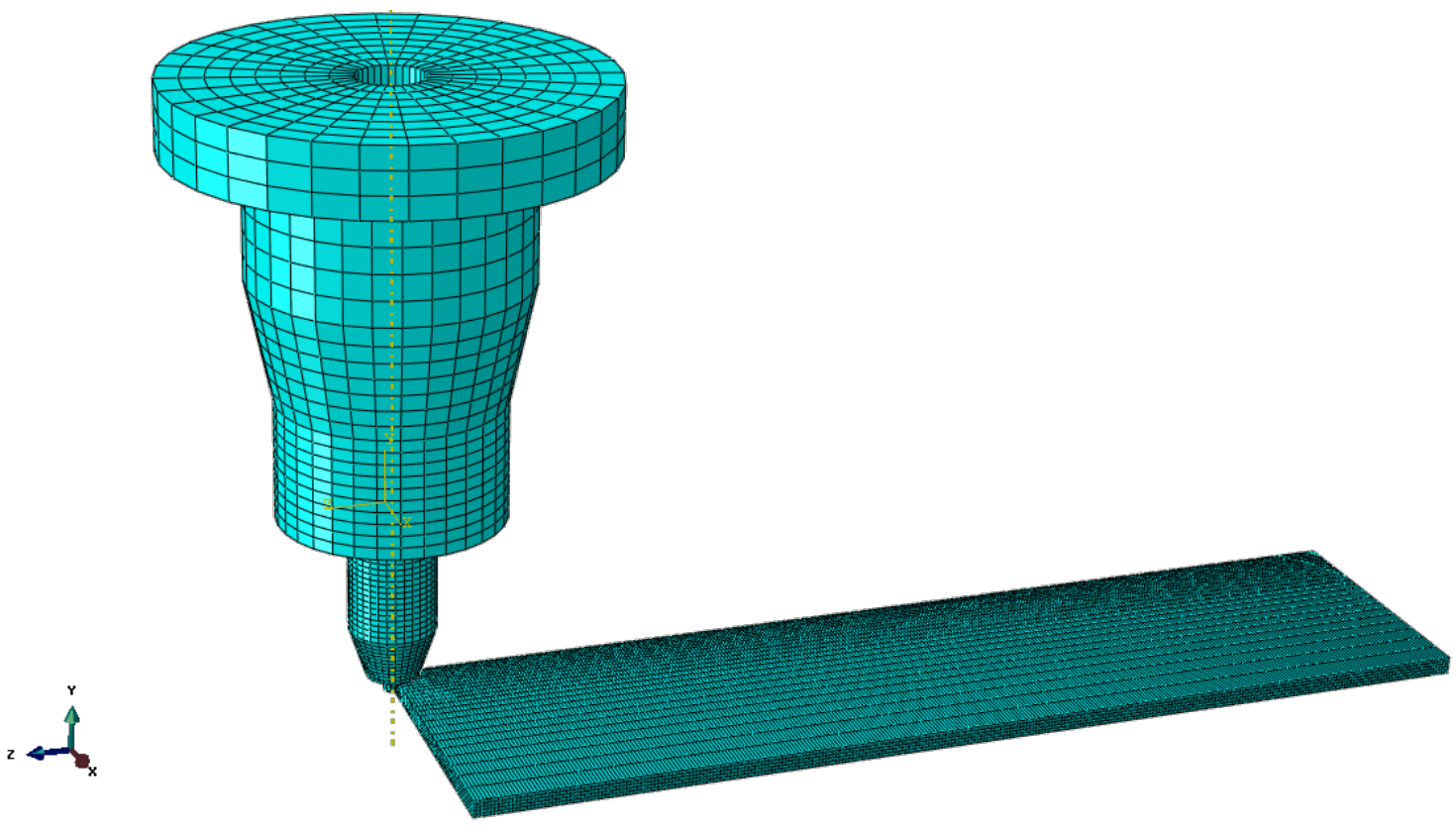

Figure 3. FE model.

Table 1 Properties of W6Mo5Cr4V2 (M2) at different temperatures [21]

\begin{tabular}{cccc}
\hline Temperature $\left({ }^{\circ} \mathrm{O}\right.$ & Density $\left(\mathrm{kg} \cdot \mathrm{m}^{-3}\right)$ & Specific heat capacity $\left(\mathrm{J} \cdot \mathrm{kg}^{-1} \cdot \mathrm{K}^{-1}\right)$ & Thermal conductivity $(\mathrm{W} \cdot \mathrm{m}-1 \cdot \mathrm{K}-1)$ \\
\hline 20 & 8160 & 420 & 19.3 \\
95 & $/$ & $/$ & 21.3 \\
200 & $/$ & $/$ & 23.5 \\
400 & 8060 & 510 & 25.6 \\
540 & $/$ & $/$ & 27.0 \\
600 & 8000 & 600 & $/$ \\
675 & $/$ & $/$ & 28.9 \\
\hline
\end{tabular}

Table 2. Physical properties of FSW tool materials for steel welding.

\begin{tabular}{cccc}
\hline Tool material & Density $\left(\mathrm{kg} \cdot \mathrm{m}^{-3}\right)$ & Specific heat $\left(\mathrm{J} \cdot \mathrm{kg}^{-1} \cdot \mathrm{K}^{-1}\right)$ & Conductivity $\left(\mathrm{W} \cdot \mathrm{m}^{-1} \cdot \mathrm{K}^{-1}\right)$ \\
\hline WC & $15600[22]$ & $203[23]$ & $110[23]$ \\
W- $25 \%$ Re & $19700[24]$ & $140[24]$ & $60[25]$ \\
PCBN & $3450[26]$ & $793[26]$ & $100 \sim 250[27]$ \\
\hline
\end{tabular}


Table 3 Thermal efficiency of friction stir welding from literature

\begin{tabular}{|c|c|c|c|}
\hline $\begin{array}{l}\text { Thermal Efficiency of } \\
\text { Welding }\end{array}$ & $\begin{array}{l}\text { Tool material, Thermal } \\
\text { conductivity }\left(\mathrm{W} \cdot \mathrm{m}^{-1} \cdot \mathrm{K}^{-1}\right)\end{array}$ & $\begin{array}{l}\text { Workpiece material, Thermal } \\
\text { conductivity }\left(\mathrm{W} \cdot \mathrm{m}^{-1} \cdot \mathrm{K}^{-1}\right)\end{array}$ & References \\
\hline 91\% (Calculated) & Hardened tool steel, 45 & AM60, 62 & Dickerson et al.[3] \\
\hline 95\% (Calculated) & M2 tool steel, 19.5 & AA2195, 92 & Chao et al.[10] \\
\hline $87 \%$ (Assumed) & N/A & AA6061 - T651 & Khandkar et al.[11] \\
\hline 95\% (Assumed) & $\mathrm{N} / \mathrm{A}$ & AA6005A-T6, 206 & Simar et al.[12] \\
\hline $85 \%$ (Assumed) & $\mathrm{N} / \mathrm{A}$ & AA6061 & Feng et al. [13] \\
\hline $88 \%$ (Calculated) & $\mathrm{N} / \mathrm{A}$ & AA7075 T6 & Schmidt et al.[14] \\
\hline 75\% (Calculated) & $\begin{array}{l}\text { Molybdenum- and tungsten- } \\
\text { based alloy, N/A }\end{array}$ & AISI 1018 steel & Lienert et al.[15] \\
\hline $50 \%$ (Calculated) & N/A & 304L stainless steel & Zhu et al. [16] \\
\hline
\end{tabular}

For the workpiece thermal model, due to the symmetry along the welding line, only half of the plate was considered, as shown in Figure 3. The model was meshed with a finer element size towards the welding line since much greater temperature gradient occurs there [10]. The temperature dependent material properties of AA6061 and C45 carbon steel plates are given in Table 4. The simplified heat source model including shoulder and pin was used in the analysis. The shoulder heat source was assumed surface heat flux and applied to the workpiece surface that contacted the tool shoulder. The heat flux value at any point with a radius, $r$, was defined by the following equation.

$$
q_{\mathrm{r}}=\frac{3 Q_{\mathrm{S}} r}{2 \pi\left(r_{0}^{3}-r_{1}^{3}\right)}
$$

where, $\mathrm{Q}_{\mathrm{s}}$ is the heat input into the workpiece by the shoulder, $\mathrm{r}_{0}, \mathrm{r}_{1}$ are the outside and inside radii, respectively. The pin heat source was assumed volumetric heat generation and applied to the workpiece material that would have been displaced by the 
pin. An Abaqus DFLUX subroutine was generated to move the heat source in the different FSW stages.

Table 4 Physical properties of C45 carbon steel and AA6061 [21]

\begin{tabular}{ccccccc}
\hline Temperature $\left({ }^{\circ} \mathrm{C}\right)$ & \multicolumn{2}{c}{ Density $\left(\mathrm{kg} \cdot \mathrm{m}^{-3}\right)$} & \multicolumn{2}{c}{ Specific heat $\left(\mathrm{J} \cdot \mathrm{kg}^{-1} \cdot \mathrm{K}^{-1}\right)$} & \multicolumn{2}{c}{ Conductivity $\left(\mathrm{W} \cdot \mathrm{m}^{-1} \cdot \mathrm{K}^{-1}\right)$} \\
\hline & 45 steel & AA6061 & 45 steel & AA6061 & 45 steel & AA6061 \\
\hline 20 & 7826 & 2680 & $/$ & $/$ & $/$ & 176 \\
100 & 7799 & 2682 & 473 & 963 & 48 & 180 \\
200 & 7769 & 2682 & 494 & 1005 & 47 & 184 \\
300 & 7735 & 2620 & 515 & 1047 & 44 & 188 \\
400 & 7698 & 2600 & 536 & 1089 & 41 & 192 \\
500 & 7662 & 2580 & 583 & $/$ & 39 & $/$ \\
\hline
\end{tabular}

\section{Results and Discussion}

\section{Comparison of FE and experimental results}

The comparison between infrared thermal measurements and the FE temperature contour plot for steady state FSW of AA6061 is presented in Figure 4. As mentioned in a prior publication [20], the temperature values at five selected points on the tool holder were shown on the images and good agreement was found between the two set results. Thus, the heat power transferred into the tool can be calculated through the applied heat flux. When the temperature profiles in the workpiece between thermocouple measurements and the FE model prediction are in good agreement, the sum of the shoulder heat flux and pin volumetric heat generation can be seen as the total heat input into the workpiece. Figure 5 presents the temperature comparison for the aluminium workpiece at distances of $0,20,30$ and $40 \mathrm{~mm}$ from the weld centreline. 


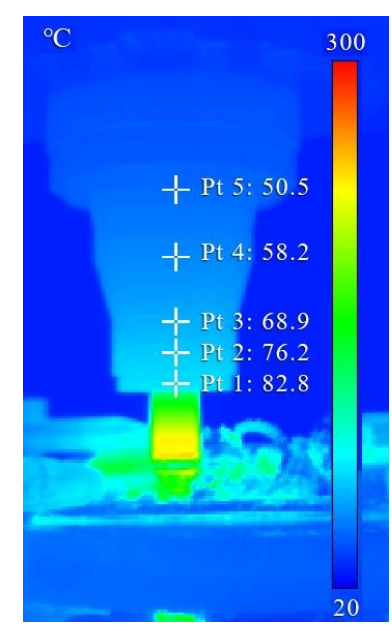

(a) Experimental temperature field

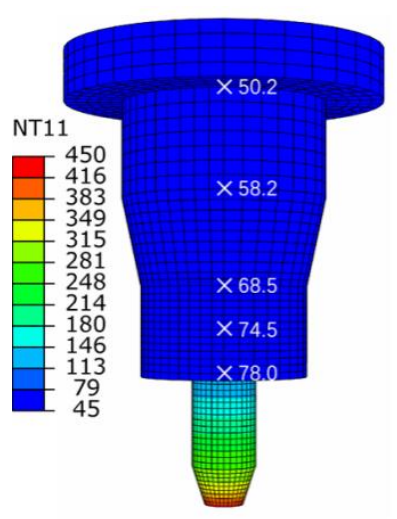

(b) FE model

Figure 4. Comparison of temperature between experiment and numerical model [20].

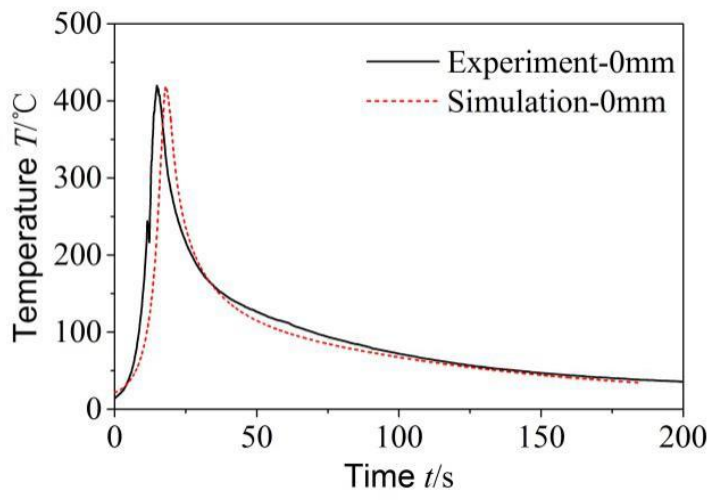

(a) Temperature at welding line

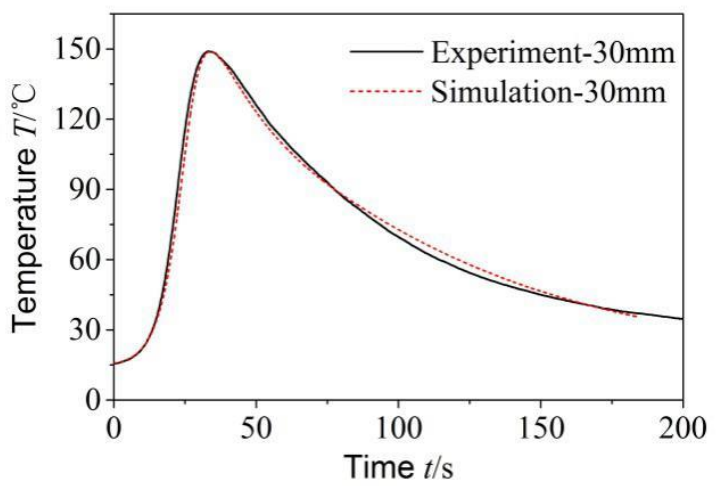

(c) Temperature at $30 \mathrm{~mm}$ from the welding line

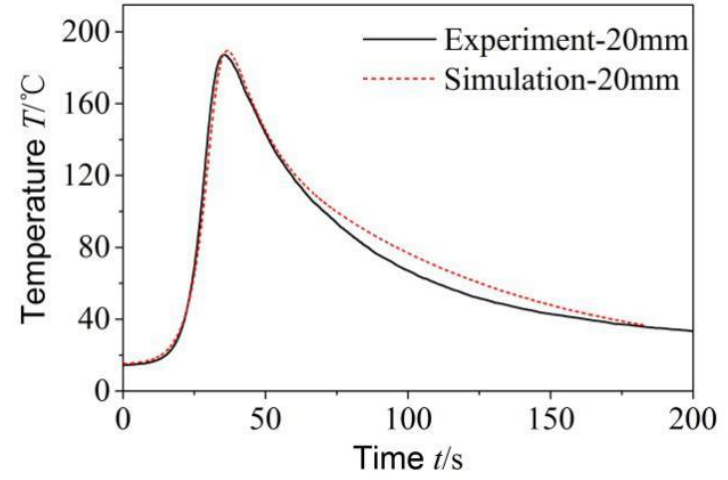

(b) Temperature at $20 \mathrm{~mm}$ from the welding line

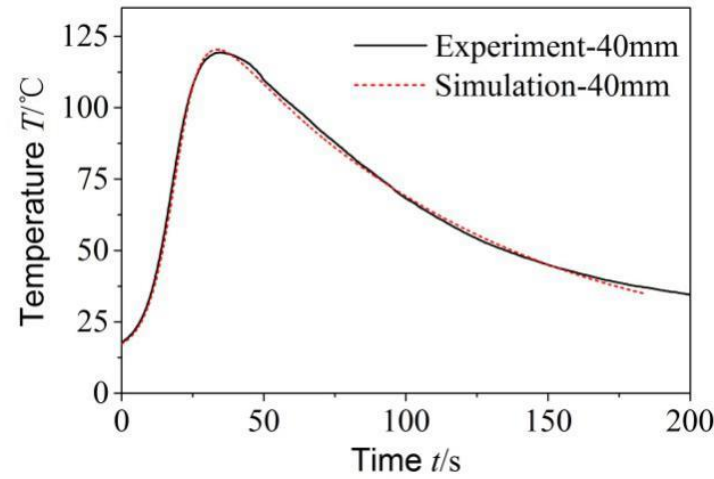

(d) Temperature at $40 \mathrm{~mm}$ from the welding line

Figure 5. Comparison between experimental and numerical temperature evolution for the AA6061workpiece. 


\section{Thermal efficiency for welding aluminium plates}

The tool heat transfer model was initially used to calculate the heat power transported to the tool. The results for the steady state welding for a rotational speed of $800 \mathrm{r} / \mathrm{min}$ and traverse speed of $30 \mathrm{~mm} / \mathrm{min}$, are tabulated in Table 5 . The heat power dissipating into the tool was $88.4 \mathrm{~W}$ when welding with the conventional tool, in contrast to the range of $42.2 \sim 74.4 \mathrm{~W}$ for the tools with thermal insulation features, i.e. tool 1 to tool 4 . There was a reduction of more than $50 \%$ heat flow into the tool.

Table 5 The heat power flowing into the tool, Q2

\begin{tabular}{ccc}
\hline FSW Tools & Heat power, $Q_{2}(\mathrm{~W})$ & Percentage of change \\
\hline Conventional tool & 88.4 & $-50.0 \%$ \\
Tool 1 & 44.2 & $-50.6 \%$ \\
Tool 2 & 43.6 & $-51.0 \%$ \\
Tool 3 & 43.3 & $-51.8 \%$ \\
Tool 4 & 42.6 & $-20.0 \%$ \\
Tool 5 & 70.7 & \\
\hline
\end{tabular}

The FSW tool 4 exhibited the best performance since it incorporated all the structure modification features, i.e. smaller main body diameter, hollow structure and grooves on tool shank. Therefore, for the following study, the welding thermal efficiency was computed and compared only for the conventional tool and Tool 4. Utilising the workpiece thermal model, the heat power input to the workpiece, Q1, was obtained by comparing to the measured temperature profile. The value was adjusted until the predicted and measured temperature evolution at the four points showed a good agreement. As mentioned earlier, Q1 incorporated two heat sources, the tool shoulder and tool pin. The detailed workpiece heat input is presented in Table 6.

Table 6. Aluminium workpiece heat input for different tools.

\begin{tabular}{cccc}
\hline FSW tools & Heat input from shoulder (W) & Heat input from probe $(W)$ & Total heat power into workpiece $($ W $)$ \\
\hline Conventional tool & 753.8 & 251.2 & 1005 \\
Tool 4 & 787.5 & 262.5 & 1050 \\
\hline
\end{tabular}


It was assumed that all of the mechanical power is converted into heat and through the workpiece and tool. The welding thermal efficiency was calculated by the following equation,

$$
\eta=\frac{Q_{1}}{Q_{1}+Q_{2}}=\frac{Q_{1}}{Q}
$$

where the total heat Q is the sum of the workpiece heat input Q1 and heat flowing into the FSW tool Q2. The calculated results are shown in Table 7. It can be seen that the workpiece heat power input increased from $1005 \mathrm{~W}$ to $1050 \mathrm{~W}$ and the heat into the tool decreased from $88.4 \mathrm{~W}$ to $42.6 \mathrm{~W}$; consequently, the welding thermal efficiency improved from $91.9 \%$ to $96.1 \%$, by using the structure modified tool 4 instead of the conventional tool. It was also found that the total heat power generated, when the FSW reached steady state conditions, was almost the same. This is attributed to the fact that the heat was generated by friction and workpiece material plastic deformation at the interface between the tool and workpiece. When the welding parameters and the tool's outer surface in contact with the workpiece remained unchanged, the total heat should be similar. Since the tool structure modification was remote from the tool pin and shoulder, this had no effect on the surface contacting workpiece.

Table 7. FSW heat power input and welding thermal efficiency for aluminium weld

\begin{tabular}{ccccc}
\hline \multirow{2}{*}{ FSW tools } & $\begin{array}{c}\text { Workpiece heat input, } Q_{1}, \\
(\mathrm{~W})\end{array}$ & Heat into the tool, $Q_{2}(\mathrm{~W})$ & Total heat, $Q(\mathrm{~W})$ & Welding thermal efficiency \\
\hline Conventional tool & 1005 & 88.4 & 1093.4 & $91.9 \%$ \\
Tool 4 & 1050 & 42.6 & 1092.6 & $96.1 \%$ \\
\hline
\end{tabular}

\section{Thermal efficiency for welding steel plates}

The nugget zone temperature typically reaches up to $1000^{\circ} \mathrm{C}$ during FSW of steel plates [15], almost twice as high than FSW of aluminium. The proportion of the heat transferred into the workpiece is lower because the conductivity of steel is lower than 
that of aluminium, leading to decreased welding thermal efficiency. In the current research, two tool designs, the conventional tool and tool 4 (Figure 2), were investigated in the same way as the welding of the aluminium plates. Three tool materials, WC, W$25 \%$ Re and pcBN were studied for the tools of both conventional and tool 4 designs. In the heat transfer models for a steel workpiece, the workpiece heat input, $Q_{1}$, was adjusted until the nugget zone temperature reached $1200^{\circ} \mathrm{C}$. This expedient treatment gave the same $Q_{1}, 1420 \mathrm{~W}$ for both the conventional tool and tool 4, since the workpiece thermal model takes only the workpiece into account, i.e. C45 steel. In the tool thermal model, difference tool heat input values, $Q_{2}$, were calculated for different tools with diverse tool materials. The computed heat input and welding thermal efficiency are presented in Table 8 .

Table 8 FSW heat power input and welding thermal efficiency for steel weld

\begin{tabular}{|c|c|c|c|c|c|}
\hline \multicolumn{2}{|c|}{ FSW tools } & \multirow{2}{*}{$\begin{array}{l}\text { Workpiece heat input, } Q_{1} \text {, } \\
\text { (W) }\end{array}$} & \multirow{2}{*}{ Heat into the tool, $Q_{2}(\mathrm{~W})$} & \multirow[t]{2}{*}{ Total heat, $Q(\mathrm{~W})$} & \multirow{2}{*}{$\begin{array}{c}\text { Welding therma } \\
\text { efficiency }\end{array}$} \\
\hline Structures & Materials & & & & \\
\hline & WC & 1420 & 745.7 & 2145.7 & $66.2 \%$ \\
\hline \multirow[t]{3}{*}{ Conventional } & $W-25 \% \operatorname{Re}$ & 1420 & 505.4 & 1950.4 & $72.8 \%$ \\
\hline & $\mathrm{pcBN}$ & 1420 & 979.0 & 2379.0 & $59.7 \%$ \\
\hline & WC & 1420 & $445.3(-40.3 \%)$ & 1865.3 & $76.1 \%$ \\
\hline \multirow[t]{2}{*}{ Tool 4} & $W-25 \% \operatorname{Re}$ & 1420 & $318.1(-37.1 \%)$ & 1738.1 & $81.7 \%$ \\
\hline & $\mathrm{pcBN}$ & 1420 & $503.6(-48.6 \%)$ & 1923.6 & $73.8 \%$ \\
\hline
\end{tabular}

The heat into the WC tool, Q2, decreased from $745.7 \mathrm{~W}$ to $445.3 \mathrm{~W}$, and the thermal efficiency increased from $66.2 \%$ to $76.1 \%$; these signify a $9.9 \%$ improvement in thermal efficiency for the new tool design. Similar trends were also found for the W$25 \% \operatorname{Re}$ and pcBN tool materials. Among the three tool materials, pcBN seemed to be the best choice because of the $48.6 \%$ heat reduction into the tool (Table 8 ). 


\section{Conclusions}

Heat transfer models for both the FSW tool and the workpiece were developed to calculate the heat transferred into the tool and the heat power input to the workpiece. The numerical model for aluminium welding was validated by experimental temperature profiles measured with an infrared camera and thermocouples for the tool and workpiece, respectively. Several thermal insulation features were applied to the new tool designs, such as low conductivity tool coating, smaller tool main body diameter, hollow structure and grooves on tool shank. It was found that the tool structures with thermal insulation features reduced heat flow into the tool as much as $50 \%$, and improved the welding thermal efficiency up to $96 \%$ for aluminium welding under the current experiment conditions. The thermal efficiency for FSW of steel was much lower than aluminium plates, ranging from $59.7 \%$ to $81.7 \%$. Compared with conventional tools, the new tool design improved thermal efficiency by up to $4.2 \%$ and $14.1 \%$ for aluminium and steel workpiece, respectively.

\section{Acknowledgement}

This research was supported by the National Natural Science Foundation of China under Grant No. 51605444 and No. 51475431.

\section{References}

[1] Rai, R., De, A., Bhadeshia, H. K. D. H., \& DebRoy, T. Friction stir welding tools. Science and Technology of welding and Joining, 2011,16(4), 325-342.

[2] Gould J E, Feng Z. Heat Flow Model for Friction Stir Welding of Aluminum Alloys. Journal of Materials Processing \& Manufacturing Science, 1998,7(2):185-194.

[3] Dickerson, T., Shi, Q., Shercliff, H. Heat Flow into Friction Stir Welding Tools, 4th International Symposium on Friction Stir Welding. Park City, Utah, USA, 14-16 May 2003.

[4] Song, M., \& Kovacevic, R. Heat transfer modelling for both workpiece and tool in the friction stir welding process: a coupled model. Proceedings of the Institution of Mechanical Engineers, Part B: Journal of Engineering Manufacture, 2004,218(1), 17-33.

[5] Zhang, Z., \& Zhang, H. W. Numerical studies of preheating time effect on temperature and material behaviours in friction stir welding process. Science and Technology of Welding and Joining, 2007,12(5), 436-448. 
[6] Hwang YM, Kang ZW, Chiou YC. Experimental study on temperature distributions within the workpiece during friction stir welding of aluminum alloys. International Journal of Machine Tools and Manufacture, 2008, 48(7): 778-787

[7] Yaduwanshi, D. K., Bag, S., \& Pal, S. Heat transfer analyses in friction stir welding of aluminium alloy. Proceedings of the Institution of Mechanical Engineers, Part B: Journal of Engineering Manufacture, 2015, 229(10), 1722-1733.

[8] Xiao, Y., Zhan, H., Gu, Y., \& Li, Q. Modeling heat transfer during friction stir welding using a meshless particle method. International Journal of Heat and Mass Transfer, 2017, 104, 288-300.

[9] Shi, L., \& Wu, C. S. Transient model of heat transfer and material flow at different stages of friction stir welding process. Journal of Manufacturing Processes, 2017, 25, 323-339

[10] Chao YJ, Qi X, Tang W, Heat transfer in friction stir welding-experimental and numerical studies. Journal of manufacturing science and engineering, 2003,125(1): 138-145

[11] Khandkar, M. Z. H., Khan, J. A., and Reynolds, A. P. Prediction of temperature distribution and thermal history during friction stir welding: input torque based model. Science and Technology of Welding and Joining, 2003,8(3), 165-174.

[12] Simar, A., Pardoen, T., and De Meester, B. Effect of rotational material flow on temperature distribution in friction stir welds. Science and Technology of Welding and Joining, 2007, 12(4), 324-333.

[13] Feng, T., and Zhang X, Three dimensional model for heat transfer and plastic flow of friction stir welding. Transactions of the China Welding Institution, 2013, 34(7): 105-108

[14] H. Schmidt and J. H. Hattel, Thermal modelling of friction stir welding, Scripta Materialia, 2008, 58 (5) 332-337.

[15] Lienert, T. J., Stellwag Jr, W. L., Grimmett, B. B., \& Warke, R. W. Friction stir welding studies on mild steel. Welding Journal, 2003,82(1), 1-S.

[16] Zhu X K, Chao YJ. Numerical simulation of transient temperature and residual stresses in friction stir welding of 304L stainless steel. Journal of materials processing technology, 2004, 146(2): 263272

[17] Reza-E-Rabby M, Tang W, Reynolds AP. Effects of thread interruptions on tool pins in friction stir welding of AA6061. Science and Technology of Welding and Joining. 2018 Feb 17;23(2):114-24.

[18] Dourandish S, Mousavizade SM, Ezatpour HR, Ebrahimi GR. Microstructure, mechanical properties and failure behaviour of protrusion friction stir spot welded 2024 aluminium alloy sheets. Science and Technology of Welding and Joining. 2018 May 19;23(4):295-307.

[19] Shin HS, de Leon M. Weldability assessment of friction stir spot welded lightweight alloys using pin and pinless tools. Science and Technology of Welding and Joining. 2016 Feb 17;21(2):99-105.

[20] Li, H., Qin, W., Liu, D., Li, Q., \& Wu, Y. Design of friction stir welding tools reducing heat flow into spindle. The International Journal of Advanced Manufacturing Technology, 2018, 94(5-8), 1925-1932.

[21] American Society for Metals, Davis JR. ASM handbook. 1. Properties and selection: irons, steels, and high-performance alloys. ASM International, 2008.

[22] CRC handbook of chemistry and physics [M]. CRC press, 2014.

[23] Liu, K., Li, X. P., Rahman, M., \& Liu, X. D. CBN tool wear in ductile cutting of tungsten carbide. Wear, 2003, 255(7-12), 1344-1351.

[24] W-25 Re Tungsten Rhenium Alloy, Annealed [DB/OL] http://www.matweb.com/search/datasheet.aspx?matguid=ec5e2badc6cf467191fd545182b139ef

[25] Jasthi B K, Arbegast W J, Howard S M. Thermal expansion coefficient and mechanical properties of friction stir welded invar $(\mathrm{Fe}-36 \% \mathrm{Ni})$, Journal of materials engineering and performance, 2009, 18(7): 925-934.

[26] Spriggs G E. 13.5 Properties of diamond and cubic boron nitride[M]//Powder Metallurgy Data. Refractory, Hard and Intermetallic Materials. Springer Berlin Heidelberg, 2002: 118-139.

[27] Meran, C., Kovan, V., \& Alptekin, A. Friction stir welding of AISI 304 austenitic stainless steel. Materialwissenschaft und Werkstofftechnik, 2007, 38(10), 829-835. 